\title{
UN NUEVO FRAGMENTO DEL ROMANCE DE CALAÍNOS
}

\author{
SAMUEl G. ARMistead \\ University of California, Davis \\ LuIS SuÁrez Ávila \\ Puerto de Santa María, Cádiz
}

Estos días los estudios romancísticos están de fiesta, pues últimamente se nos está brindando un número significativo de textos variantes -e incluso de romances previamente desconocidos- provenientes de fuentes manuscritas recién descubiertas del siglo XV y de principios del XvI; o sea, textos de fecha tan temprana que, aunque sea de forma siempre muy parcial, nos permiten vislumbrar alguna que otra faceta poco o nada conocida de las épocas latentes del género, de la prehistoria del romancero viejo, previa a la publicación de los primeros pliegos sueltos y cancioneros. Tengamos en cuenta, por ejemplo, los siguientes testimonios: El Arcebispo de Çaragoça («Arcebispo de Çaragoça / como te avias exaltado») (fechable en 1429); Las quejas de Alfonso $V$ (1448); la primera versión antigua y peninsular del Infante cautivo (c. 1505); una nueva versión de Las quejas de Jimena (comienzos del s. XVI). ${ }^{1}$

\footnotetext{
1 Véanse Encarnación Marín Padilla, "Arcebispo de Çaragoça»: Romance castellano manuscrito del año 1429, Madrid, C.S.I.C., 1997; Marín Padilla y José Manuel Pedrosa, «Un texto arcaico recuperado para la historia del Romancero: Una versión aragonesa manuscrita (1448) de Las quejas de Alfonso V», Revista de Literatura Medieval (Alcalá de Henares) (en prensa); El infante cautivo (Mariano de la Campa y Belinda García Barba, "Versiones medievales inéditas de varios romances en un romancerillo manuscrito fragmentario», Medievalia, 25 [1997], págs. 26-42). Esta versión peninsular del Infante cautivo altera totalmente nuestras suposiciones acerca del romance, que, hasta la fecha, se conocía exclusivamente a base de textos judeo-españoles de Oriente (Samuel G. Armistead y Joseph H. Silverman, En torno al romancero sefardi: Hispanismo y balcanismo de la tradición judeo-española, Madrid, S.M.P., 1982, págs. 73-75). La acompañan en el Ms. estudiado por Campa y García Barba nuevas y significativas variantes de otros romances tradicionales o tradicionalizados: Rosa Fresca, Fonte Frida y Maldita seas ventura. La nueva versión de Las quejas de Jimena, descubierta por Charles Faulhaber, la daremos a conocer Arthur Lee-Francis Askins, Charles
} 
Merece, según creemos, agregarse a los textos romancísticos aquí citados un nuevo fragmento variante del romance de Calaínos, que acaba de darse a conocer en la edición que de la Historia de Sevilla del Bachiller Luis de Peraza (Bibl. Colombina 57/6/34; copia fechada en 1535) ahora ha publicado Silvia María Pérez González. A propósito del nombre de Sevilla y de su «antiquísimo origen», el Bachiller nos ofrece el siguiente comentario:

Duró en perseverancia este nombre Híspalis por muchas edades y siglos hasta que por ocultos juicios divinos y, según las verdaderas crónicas de España dicen, causándolo los pecados de los godos y gentes de España, toda esta provincia hespérica fue entregada a las manos de los infieles moros y a vueltas aunque cuasi a la postre de todas la real ciudad de Sevilla. Y como estos descendientes de Agar tenían mucha voluntad de oscurecer las ilustres memorias que en la tierra de los cristianos se hallaban porque en todo pereciese este nombre Híspalis, pusiéronle nombre Sandueña. De lo cual hace memoria un antiquísimo romance que llaman de Calaínos el cual comienza así: Ya cabalga Calaínos a sombra de una verde oliva (que era de la sombra de un aceituno), mirando estaba a Sandueña, que muy bien le parecia. Lo cual se entiende que como esta tierra era de moros, aquel moro cabalgó a sombra de algún aceituno de los que están en el altura del Axarafe, y de allí miraban a Sandueña, que es Sevilla, que se puede muy bien ver de aquel lugar. Solamente hallo este nombre escrito en este lugar. ${ }^{2}$

Faulhaber y yo en un artículo que actualmente tenemos en preparación: «A New Version of Las quejas de Jimena». Para el descubrimiento de Las quejas de Jimena, véase Charles B. Faulhaber, "Celestina de Palacio: Madrid, Biblioteca de Palacio, MS 1520», Celestinesca, 14:2, 1990, págs. 3-39: 4. También cabe mencionar, en el presente contexto, la versión manuscrita distintiva de Castellanos y leoneses, igualmente de principios del siglo XVI, dada a conocer por Brian Dutton y Ch. B. Faulhaber («The 'Lost' Barrantes Cancionero of FifteenthCentury Spanish Poetry», Florilegium Hispanicum: Medieval and Golden Age Studies presented to Dorothy Clotelle Clarke, ed. John S. Geary, Charles B. Faulhaber y Dwayne E. Carpenter, Madison, Hispanic Seminary of Medieval Studies, 1983, pág. 196) y, aunque la copia sea mucho más tardía, también el sensacional descubrimiento de la primera versión antigua conocida de La muerte del príncipe don Juan (texto de 1578+) (C. Ángel Zorita, Ralph A. DiFranco, y José J. Labrador Herraiz, Poesías del Maestro León y de Fr. Melchor de la Serna y otros [S. XVI]: Códice núm. 961 de la Biblioteca Real de Madrid, Cleveland, Ohio, Cleveland State University, 1991, págs. 188-189, núm. 59). Las referencias que aquí remiten a «Primav(era)» reflejan el texto de la 2. ${ }^{\mathrm{a}}$ ed.: Fernando J. Wolf y Conrado Hofmann, Primavera y flor de romances, 2. ${ }^{a}$ ed., Marcelino Menéndez Pelayo, Antología de poetas líricos castellanos, VIII, «Ed. Nac.», XXIV, Santander, C.S.I.C., 1945.

2 Véase Silvia María Pérez González (ed.), Historia de la ciudad de Sevilla del Bachiller Luis de Peraza, Sevilla, Excmo. Ayuntamiento, 1997. El título completo del Ms. 57/6/34 reza: Antiquisimo origen de la ciudad de Sevilla. Su fundación por Hércules tebano, y posesión de Reyes que la habitaron en todos tiempos hasta ser poseida de los moros. Compuesta por el Bachiller Luis de Peraza, natural desta ciudad de Sevilla. Año de 1535. Huelga decir que nuestro autor es de la misma distinguida estirpe sevillana que el joven y malogrado conquistador de las Islas Canarias, muerto en La Palma hacia 1448 y lamentado en las hermosas Endechas a la muerte de Guillén Peraza, cuya belleza ahora encarece un magistral estudio de Francisco Rico, Texto y contextos: Estudios sobre la poesía española del siglo $\mathrm{XV}$, Barcelona, Crítica, 1990, págs. 95-158; y sobre los Peraza: 112-117. 
Con la fecha de 1535, huelga decir que estamos ante dos versos - cuatro octosílabos- anteriores a la publicación del Cancionero de romances de Amberes (sin año) (circa 1548) y de la Silva de Sirenas de Enríquez de Valderrábano (1547), donde constan las dos formas del romance de Calaínos conocidas hasta el momento. ${ }^{3}$ Pero en lo que se refiere a la fecha original de la Historia sevillana, viene muy a cuento una anotación marginal que se recoge en el folio 300 de la copia de esta Historia manuscrita existente en la Biblioteca Nacional, Madrid (Ms. 10532), en la que puede colegirse que la redacción de la obra comenzó entre 1476 y 1486, por una mención que se hace de que las monjas del convento de Madre de Dios vivían frente a la Puerta antigua de Triana «(que hoy está cerrada) y dichas santas religiosas entraron a vivir en dicho sitio el año de 1476 y salieron de él el de 1486. Con que en este intermedio se escribió esta relación y más cerca del 76 que del 86, por lo que da de sí el estilo de ella». Así pues, como la transcripción de los dos versos del romance de Calaínos figura en el «Libro Segundo» de la Primera Parte, debemos pensar que la cita del romance sea al menos de finales del siglo XV, entre 1476 y 1486. Estamos, por lo tanto, ante un fragmento romancístico de muy respetable antigüedad:

$$
\begin{aligned}
& \text { Ya cabalga Calaínos a sombra de una verde oliva } \\
& \text { mirando estaba a Sandueña }
\end{aligned}
$$

Los dos avatares de Calaínos - del Cancionero de Amberes, sin año, y del vihuelista - que hasta la fecha conocíamos, ostentan las siguientes lecturas:

$$
\begin{array}{lc}
\text { Ya caualga Calaynos } & \text { ala sombra de vna oliua } \\
\text { el pie tiene enel estribo } & \text { caualga de gallardia } \\
\text { mirando estaua a Sansuena } & \text { el arraual con la villa }
\end{array}
$$

(Amberes, sin año, fol. 92 vo. = Primav. 193)

Ya cavalga Calaynos a la sombra de una verde oliva

sin poner pie en el estribo, cavalga de gallardía.

(Valderrábano, núm. 21$)^{4}$

\footnotetext{
${ }^{3}$ Citamos de las ediciones de Ramón Menéndez Pidal, Cancionero de romances impreso en Amberes sin año, Madrid, C.S.I.C., 1945, y Enríquez de Valderrábano, Libro de música de vihuela, intitulado Silva de Sirenas (Valladolid, 1547), 2 tomos, ed. Emilio Pujol, Barcelona, C.S.I.C., 1965, núm. 21

${ }^{4}$ Constan otras muchas impresiones y reimpresiones antiguas de Ya cavalga Calainos. Tengamos en cuenta los siguientes pliegos sueltos (según constan en Antonio Rodríguez-Moñino, Nuevo diccionario bibliográfico de pliegos sueltos poéticos [Siglo XVI], ed. Arthur L.-F. Askins y Víctor Infantes, Madrid, Castalia, 1997): núm. 431: pliego que fue de la Huth Library (de paradero desconocido); 1028: Pliegos poéticos españoles de la British Library, Lon-
} 
Resulta claro que don Luis de Peraza, en pleno afán de defender el antiquísimo nombre de Sevilla y trayendo a colación el «antiquísimo romance» de Calaínos, no iba a acudir a más autoridad que la de su propia florida memoria, que, como cualquier letrado (o iletrado) del siglo $\mathrm{xV}-\mathrm{O}$ bien de los siglos áureos- tenía generosamente provista de versos orales y tradicionales de la más diversa índole. ${ }^{5}$ Está visto, pues, que don Luis, al

\begin{abstract}
dres, ed. Arthur L.-F. Askins, 4 tomos, Madrid, Joyas Bibliográficas, 1989-1991, III, pág. 1369; 1029: pliego de la Bibliothèque Nationale de Paris (Y2-865); 1030: Pliegos poéticos españoles en la Universidad de Praga, prólogo de Ramón Menéndez Pidal, 2 tomos, Madrid, Joyas Bibliográficas, 1960, I, pág. 73; 1031: pliego que fue de la colección de Salvá, entre otros (de paradero desconocido). Entre los textos incluidos en cancioneros, arrancan cinco reimpresiones de la ed. de Amberes (sin año): Millis 1550, Amberes 1550, 1555, 1568 y Lisboa 1581; el romance también consta en la Silva de romances $\left(3 .^{\mathrm{a}}\right.$ parte, 1551). De estos textos, los que hemos visto (British Library, París, Praga, Amberes, sin año, Amberes, 1550 y Silva) no ostentan en los versos que nos interesan lecturas sensiblemente diferentes de las de Amberes, sin año: «a sõbra» (B́ritish); «a sombra» (París, Praga); «los pies» (Silva). Agradecemos de todo corazón a nuestro amigo y colega, el profesor Arthur L.-F. Askins, quien, con su característica generosidad, nos ha facilitado una reproducción fotográfica del pliego de París. En los Disbarates (sic) de Gabriel de Saravia, consta el primer verso de nuestro romance con la variante un oliva: "ya caualga calaynos / ala sombra de vn oliva» (Pliegos de la British Library, II, pág. 873). Para Amberes 1550 y la Silva, hemos tenido a la vista las eds. de Rodríguez-Moñino, Cancionero de romances (Anvers, 1550), Madrid, Castalia, 1967; y Silva de romances (Zaragoza, 1550-1551), Zaragoza, Cátedra Zaragoza, 1970; para las ediciones antiguas de los cancioneros: Rodríguez-Moñino, con Arthur L.-F. Askins, Manual bibliográfico de cancioneros y romanceros, 4 tomos, Madrid, Castalia, 1973-1978, II, pág. 817. Para texto y música de la versión de Enríquez de Valderrábano, véase también la ed. de Guillermo Morphy y Ferriz de Guzmán, Les luthistes espagnols du XV siècle (Die spanischen Lautenmeister des 16. Jahrhunderts), 2 tomos, Leipzig, Breitkopf \& Härtel, 1902, II, pág. 162. Como de costumbre, Damián López de Tortajada, en su Floresta de varios romances (Valencia, 1652, ed. Antonio Rodríguez-Moñino, Madrid, Castalia, 1970, pág. 210), cambia arbitrariamente y sin beneficio poético las lecturas tradicionales de nuestros versos: "Ya caualga Calainos / a la sombra de vna oliua, // vn pie tiene en el estriuo, / subia de gallardia. // Mirando estaua a Sansueña / su gran torre con la villa». Para reimpresiones ulteriores: Rodríguez-Moñino, Manual de cancioneros, IV, pág. $257 a$.

5 Otro caso parecido - aunque sea un siglo más moderno- es el de los versos tradicionales, con que el embajador de Felipe II en París, Tomás Perrenot de Chantonnay, procuraba confundir a posibles descifradores, al intercalar sobre la marcha trozos de romances y villancicos en sus despachos cifrados. (Tienen en preparación una edición Diego Catalán y José Manuel Pedrosa, Cancionero en cifra de Perrenot, embajador de Felipe II en Francia [1562].) Otro caso análogo lo constituyen las pruebas de pluma, que obviamente no copian textos manuscritos ni impresos, sino que salen espontáneamente y al azar de la memoria del que, con impaciencia y con ganas de poner manos a la obra, procura poner a prueba su pluma y luego emprender su tarea. Véanse Armistead ( $¿$ Existió un romancero de tradición oral entre los moriscos?», Actas del Coloquio Internacional sobre Literatura Aljamiada y Morisca, ed. Alvaro Galmés de Fuentes [Madrid, Gredos, 1978], págs. 224-227; Juan Carlos Conde López, «Otro testimonio manuscrito de un villancico tradicional», JHR, 1, 1992-1993, págs. 203-206; Mari Carmen García, «Romances, villancicos y refranes en unos garabatos del siglo $\mathrm{XV}$ al XVI», La Corónica, 22:2, 1993-1994, págs. 123-131. Que el romance de Calaínos sea «antiquísimo» es, en todo caso, muy relativo, siendo como es una refundición radical, muy libre y tardía, de antecedentes épicos lejanos.
\end{abstract}


citar el romance, lo hace de memoria y a vuelo de pluma, como quien lo conoce de tradición oral y lo tiene muy oído y recordado.

Por lo tanto, nuestros versos - aparte de ser anteriores en la copia conservada (1535) y, en su origen, muy anteriores (1476-1486) a las versiones del tipo de Amberes, sin año (y afines) y de Valderrábano- también aportan interesantes lecturas variantes: Peraza trae la «verde oliva», como en el vihuelista, pero en contra de Amberes; se salta el v. 2 del Cancionero (cuyo segundo hemistiquio, por otra parte, sí consta en la Silva de Sirenas); por etimología popular, convierte Sansueña -de resonancias épico-francesas- en Sandueña; y, como segundo hemistiquio del v. 2, nuestro fragmento trae una fórmula épico-romancística desconocida en la única versión amplia del Calaínos de que hoy disponemos (la de Amberes, sin año y sus congéneres). ${ }^{6} \mathrm{O}$ sea estamos ante un vestigio de una versión tradicional distinta de las que se documentan a mediados del siglo XVI.

\footnotetext{
${ }^{6}$ El topónimo Sansueña $(<$ provenzal Sansuenha $<$ Saxonia; en francés medieval Sansoig$n e$, entre otras muchas variantes) remonta a adaptaciones españolas perdidas de la epopeya medieval francesa, La chanson des Saisnes. Véanse Edmund Stengel y Friedrich Menzel (ed.), Jean Bodels Saxenlied, 2 tomos, Marburg, N. G. Elwert, 1906-1909; Annette Brasseur (ed.), Jehan Bodel, La Chanson des Saisnes, 2 tomos, Ginebra, Droz, 1989; Ramón Menéndez Pidal, Los godos y la epopeya española: "Chansons de geste» y baladas nórdicas, Madrid, Espasa-Calpe, 1956, págs. 204-207. En el Quijote (II: 26), Maese Pedro identifica Sansueña con Zaragoza, pero, por la asociación de Sansueña con un ambiente musulmán - tradicional ya desde la misma chanson de geste francesa - no extraña nada que también haya podido atribuirse el topónimo a Sevilla, dado, claro está, el fenómeno del traslado gradual de los topónimos épico-romancísticos cada vez más hacia el sur — digamos la «meridionalización» del romancero- al seguir el compás de la Reconquista. Véase Samuel G. Armistead, Joseph H. Silverman, e Israel J. Katz, Folk Literature of the Sephardic Jews, 3 tomos, Berkeley-Los Ángeles, University of California Press, 1971-1994, III, págs. 174 y 280-281, n. 67. Nótese cómo, en el romance del Palmero, el protagonista sale huyendo de Mérida, donde le han tenido cautivado los moros, pero resulta, al parecer, que esta ciudad se encuentra "allende el mar» y alli le han presentado - con muy gratos resultados - «a la infanta de Sansueña» (Primav. 195.38-39). Tampoco extraña la transformación popular-etimológica del topónimo, pues, en Gaiferos y Melisenda, de acuerdo con la tradición moderna gitano-andaluza, encontramos las formas Sarsueña y Sagüeña (compárese Teresa Catarella, El romancero gitano-andaluz de Juan José Niño, Sevilla, Fundación Machado, 1993, pág. 33). En último término, el romance de Calainos se relaciona muy lejana y «libérrimamente» con la tradición épica de la Chanson des Saisnes, pero todo lo del desafio de los pares de Francia está basado en una refundición provenzal del Fierabrás. Véase lo que dicen Manuel Milá y Fontanals (De la poesía heroico-popular castellana, Barcelona, Álvaro Verdaguer, 1896, págs. 357-358; o bien Milá y Fontanals, De la poesía heroico-popular castellana, ed. Martín de Riquer y Joaquín Molas, Barcelona, C.S.I.C., 1959, págs. 446-447); Marcelino Menéndez Pelayo (Tratado de los romances viejos, 2 tomos, Antología de poetas líricos castellanos, VI-VII, «Ed. Nac.», XXIIXXIII, Santander, C.S.I.C., 1944, pág. 327) y Menéndez Pidal (Romancero hispánico: hispano-portugués, americano y sefardi, 2 tomos, Madrid, Espasa-Calpe, 1953, pág. 264 y n. 41). Respecto a la popularidad de nuestro romance, Milá recoge una «sabida... locución proverbial: "Esto no vale las coplas de Calainos»»), citada por el P. Martín Sarmiento (Milá, De la poesía, 1896, págs. 17, n. 1; 357, n. 1; ed. de 1959: págs. 66, n. 1; 447, n. 1).
} 
Otra prueba de la oralidad de nuestro fragmento - si es que falta hiciera- es el invariable carácter formulístico de sus cuatro hemistiquios. La fórmula inicial, en la que el protagonista se presenta ya en marcha y cabalgando en busca de su destino, es muy conocida:
Caualga diego laynez
Caualga doña Ginebra
Ya caualga Diego Ordoñez
ya caualga Lançarote
Ya caualgaua Arnaldos
en vn cauallo ligero
la silla era de oro
$y$ el freno de Toledo.
Ya caualgaua Arnaldos
y vn ligero cauallo
la silla era de oro
y el freno Toledano. ${ }^{7}$

al buen rey besar la mano

(Amberes, sin año, fol. 155 vo. = Primav. 29)

y de Cordoua la rica

(Silva, 1550, pág. 427)

del real se auia salido

(Amberes, 1550, pág. $216=$ Primav.

ya caualga y va su via

(Amberes, 1550, pág. $283=$ Primav. 147)

Una hoja suelta manuscrita, de mediados del siglo XVI, que ahora nos dan a conocer Mariano de la Campa y Belinda García Barba (pág. 41), nos aporta otro interesantísimo ejemplo, en forma de coplas octosilábicas paralelísticas:

\begin{abstract}
${ }^{7}$ Desconocemos el origen de estas coplas romancísticas. ¿Se tratará de algún relato métricamente afin a los del Veneno de Moriana o de Don Bueso y su hermana (en su avatar hexasilábico y arcaico: Asturias y sefardíes)? Por otra parte, otro fragmento proveniente de la misma hoja suelta, sí que se puede identificar, aunque en concreto, la narración que representa hoy por hoy siga siendo desconocida. Mariano de la Campa y Belinda García Barba dan a conocer estos cuatro hemistiquios: «E[n] calças está el co[n]de / y en un jubó[n] de co[n]traye // el pan tenía e[n] la mano / los canes q[u]ería çeuare» («Versiones medievales inéditas», pág. 41). Sea el que fuera el relato a que estos versos pertenecen, no cabe duda que se trata una variante del íncipit sefardí, «kalšaš 'estaba'l konde», del himnario de Israel Najara editado por Mordechai Zevi Friedländer (Hymnen des R. Israel Nagarah: Nache einer äusserst seltenen Handschrift der k.k. Hofbibliothek zu Wien, Vienna, L.C. Zamarski-C. Dittmarsch, 1858, pág. 46). No acertamos Joseph Silverman y yo («El antiguo Romancero sefardí: Citas de romances en himnarios hebreos [Siglo XVI-XIX]", NRFH, 30 [1981], págs. 469-470: núm. 17), al asociar el hemistiquio con el romance de la Prisión del conde Vélez. Los versos de la hoja suelta exigen que se corrija tal identificación. Desconocemos el origen de estos versos, pero queda muy claro que se trata de una situación muy distinta de la de nuestro romance, donde se sorprende al amoroso conde in flagrante delicto con la prima carnal del rey don Sancho el Deseado (Juan Timoneda, Rosas de romances [Valencia, 1573], ed. Antonio Rodríguez-Moñino y Daniel Devoto, Valencia, Castalia, 1963, fol. lij vo.; Diego Catalán, Por campos del ro-
\end{abstract}


También se dan versos análogos en otras tradiciones lingüísticas: «Her Oluf hand rider saa vide» (Señor Oluf cabalga tan lejos...); ${ }^{8}$ «Es ritt ein Reiter wol gemut» (Un caballero cabalgó bien contento....). ${ }^{9}$ Aun más sugerentes son las siguientes lecturas danesas (entre otros muchos ejemplos que se podrían citar): «Hr. Peder han rider i grønnen Lund» (Sr. Pedro cabalga en la verde floresta...) (Grundtvig, núm. 47R: t. IV, 841); o bien: «Hr. Peder han rider i Rosenslund» (Sr. Pedro cabalga en el boscaje de rosas...) (Grundtvig, núm. 37M: t. IV, 796). ${ }^{10} \mathrm{Y}$ a este propósito, también conviene tener presente lo que puede ser el primer testimonio que tenemos - en toda Europa - de un canto baládico, aunque sea sólo en traducción latina: «Equitabat Bovo / per silvam frondosam, // Ducebat sibi / Merswinden formosam. // Quid stamus? / Cur non imus?» (Cabalga Bovo / por el frondoso bosque. // Consigo llevaba / a la hermosa Merswinda. // ¿Qué hacemos aquí parados? / ¿Por qué no nos marchamos?) (Meier, Balladen, I, 12-13). El incidente descrito (no interesa especificar los detalles en el presente contexto) se localiza en Alemania y puede fecharse en el año 1020. La coincidencia de «Equitabat» y «silvam frondosam» con «Cabalga» y «a sombra de una verde oliva» - $\mathrm{y}$ con los ejemplos daneses y eslavos- no deja de ser de lo más sugerente: un mismo lenguaje poético que ya en la alta Edad Media se extiende por todo el occidente de Europa.

$\mathrm{Y}$ no deja de ser muy sugerente también el siguiente verso - verso introductorio, por cierto - que se da como comienzo de la laisse XXVIII de la Chanson de Roland, donde el traidor, o bien el anti-héroe Ganelón, se representa cabalgando debajo de un encumbrado olivo:

Guenes chevalchet suz une olive halte.

(ed. Whitehead, v. 366) ${ }^{11}$

\begin{abstract}
mancero, Madrid, Gredos, 1970, págs. 167-185). Para más datos y más ejemplos de la cabalgada como comienzo de romances, véase Rodríguez-Moñino, Manual de cancioneros, II, núms. 353, 817. Compárese también, en el poema burlesco, Aposento de Juvera: "Ya cavalga renegando / Sayavedra con gran saña» (Juan Alfonso Bellón Cazabán y Pablo Jauralde Pou, Cancionero de obras de burlas provocantes a risa, Madrid, Akal, 1974, pág. 33).

${ }^{8}$ Sven Grundtvig, con Axel Olrik, Hakon Grüner-Nielsen, et al., Danmarks gamle Folkeviser, 12 tomos, Copenhagen, Universitets-Jubilaeets Danske-Samfund, 1966-1976, núm. 47B.

${ }^{9}$ John Meier, Balladen, 2 tomos, Darmstadt, Wissenschaftliche Buchgesellschaft, 1964, II, pág. 134, núm. 67.

${ }^{10}$ Nótense también los siguientes ejemplos en baladas de los vendos o sorbos (islotes lingüísticos eslavos del este de Alemania). Por razones tipográficas, citamos sólo por la traducción alemana: «Junker Bursch reitet dahin und daher» (El joven noble cabalga de allí y de aquí); «Reitet en Reiter durch den Wald, Reitet hin durch den grünen Wald» (Un caballero cabalga por el bosque, cabalga allí por el bosque verde) (Leopold Haupt y Johann Ernst Schmaler, Volkslieder der Wenden in der Ober- und Nieder-Lausitz, 2 tomos, Grimma, J.M. Gebhardt, 1841-1843, tomos I, núm. LXXV; II, núm. VI).

${ }^{11}$ Las versiones y traducciones ulteriores de la Chanson de Roland, o no documentan el pasaje que aquí nos interesa, o bien suelen alterar el verso y su formulismo: "Civalça Gayne di et noite a la luna» (MS de Venecia IV: ed. Raoul Mortier, Les textes de la Chanson de Roland, 10
\end{abstract}


No creemos que el acuerdo entre el texto francés y nuestros romances y baladas sea fortuito ni pura coincidencia. Estos poemas comparten un mismo código poético, un mismo sistema formulístico, de antiquísimo abolengo, de vigencia multi-secular. Y estos poemas orales, a través de los siglos, se dan la mano, además, con los versos latino-alemanes del siglo XI, en último término también de origen oral.

Igualmente formulístico y tradicional es el ya actualizador que introduce nuestro fragmento y las demás versiones de Calaínos. Entre otros muchos ejemplos, compárense:

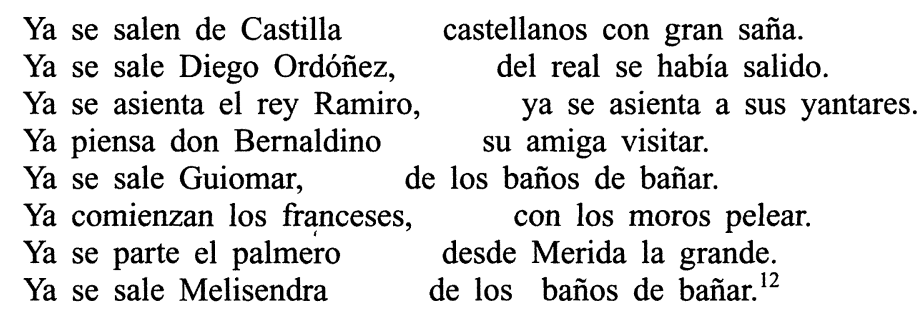

tomos, París, «La geste francor», 1940-1944, II, pág. 9, v. 283); «Guenes chevauche qi mot a fier corage» (MS de Chateauroux: Mortier, IV, pág. 16, v. 544). "Genelun truriclichen reít» (G. cabalga tristemente) (Rolandslied del fraile Konrad: ed. Carl Wesle y Peter Wapnewski, Das Rolandslied des Pfaffen Konrad, Tübingen, Max Niemeyer, 1985, v. 1750). El MS francés perdido, fuente de la traducción al nórdico antiguo, la Saga af Runzivals bardaga, había de estar más cercano a la clásica versión de Oxford: «Les messagers du roi païen étaient sous un olivier et s'apprêtaient au voyage. Le comte Ganelon entreprit le voyage avec eux» (Paul Aebischer, Rolandiana borealia: La «Saga af Runzivals bardaga» et ses dérivés scandinaves comparés à la "Chanson de Roland»..., Lausanne, F. Rouge, 1954, pág. 115; Constance B. Hieatt [trad.], Karlamagnús Saga: The Saga of Charlemagne and His Heroes, 3 tomos, Toronto, Pontifical Institute of Mediaeval Studies, 1975-1980, III, pág. 235). Sobre las variantes del v. 366, véase lo que dice Cesare Segre ( $\mathrm{La}$ Chanson de Roland, trad. Madeleine Tyssens, 2 tomos, Ginebra, Droz, 1989, II, pág. 54).

${ }^{12}$ Los íncipits citados son de Primavera 25, 47b, 99, 149, 178; Marcelino Menéndez Pelayo, "Apéndices y suplemento a la Primavera y flor de romances de Wolf y Hoffmann», Antología de poetas líricos castellanos, IX, «Ed. Nac.», XXV, Santander, C.S.I.C., 1945, pág. 67; Pliegos de Praga, I, 6b, 7a. Compárese también, en las Guerras civiles de Granada de Ginés Pérez de Hita: «Ya repican en Andújar, / en la Guardia es el rebato, // ya se salen de Jaén / quatro-cientos hijos de algo» (Ginés Pérez de Hita, Guerras civiles de Granada: Primera parte, ed. Paula Blanchard-Demouge, Madrid, E. Bailly-Baillière, 1913, pág. 169; Guerras civiles de Granada: Primera parte, ed. Shasta M. Bryant, Newark, Delaware, «Juan de la Cuesta», 1982, pág. 169, cap. 13). Para otros muchos ejemplos, véase Rodríguez-Moñino, Manual de cancioneros, II, núms. 817-825. Nótense además los siguientes textos épicos: "Ya crieban los albores / e vinie la mañana» (Ramón Menéndez Pidal [ed.], Cantar de Mio Cid: Texto, gramática y vocabulario, 3 tomos, Madrid, Espasa-Calpe, 1944-1946, v. 456); «Hya va el mandado / por las tierras todas» (v. 939); «Yas espiden / e pienssan de cavalgar» (v. 1448); «Ya quieren cavalgar, / en espidimiento son» (v. 2591); "Ya van por la infanta / a poder de cavallo» (Mocedades de Rodrigo: Ramón Menéndez Pidal, Reliquias de la poesía épica española, acompañadas de «Epopeya y Romancero, l», ed. Diego Catalán, 2da ed., Madrid, Gredos, 1980, v. 962); "Ya se va Ruy Díaz / a lo sus vassallos» (v. 1051); "Ya son muertos los infantes / ¡Dios les aya las almas! (Infantes de Lara: Reliquias, v. 24). Sobre el ya actualizante, véase Menéndez Pidal, Romancero hispánico, I, pág. 271). 
El segundo hemistiquio de nuestro romance también es formulístico, como acabamos de ver. Así, al comienzo del enigmático romance de Alfonso Ramos: «Estaua la linda infanta / a la sombra de vna oliua» (Amberes, sin año, fol. 193 vo. = Primav. 118) y, en el romance de Lanzarote (Nunca fuera caballero), cuando el protagonista se enfrenta con su enemigo, el Orgulloso: «topo con el argulloso / debaxo de vn verde pino» (Amberes, sin año, fol. 229 ro. = Primav. 148). ${ }^{13}$ Aparte de que los protagonistas busquen abrigo bajo árboles (olivos, pinos, etc.), también llama la atención por su formulismo el sintagma a (la) sombra de. Así, en el romance de Conde Claros y la infanta, el desgraciado y traicionero cazador descubre a los amantes en un vergel, «ala sombra de vn acipres / debajo de vn rosal» (Amberes, sin año, fol. 83 = Primav. 190), mientras que, en Melisenda insomne, cuando la atrevida protagonista se dirige al aposento de su amado conde Ayruelo, «a sombra va de tejados / que no la conozca nadie». ${ }^{14}$ Así mismo, en versiones sefardíes orientales del romance bíblico del Robo de

${ }^{13}$ En la épica francesa, los olivos, pinos y espinos suelen facilitar, tanto a cristianos como a moros, un formulístico lugar ameno, donde pueden sentarse o acostarse a la sombra. Así en La Chanson de Roland: «Desuz un pin, delez un eglenter / ... La siet li reis ki dulce France tient» (Frederick Whitehead [ed.], La Chanson de Roland, Oxford, Basil Blackwell, 1970, vv. $114,116)$; «desuz un pin en est li reis alez» (v. 165); «Li empereres s'en vait desuz un pin» (v. 168); «Un faldestoet out suz l'umbre d'un pin / ... La fut li reis ki tute Espaigne tint» (o sea: el rey Marsil) (vv. 407, 409); cuando Roldán se siente en trance de morir: «Desuz un pin i est alét curant» (v. 2357); «Li quens Rollant se jut desuz un pin» (v. 2375); al huir de Zaragoza, el rey Marsil se para a descansar debajo de un olivo: «Suz un'olive est descendut en l'umbre» (v. 2571); los mensajeros musulmanes dejan sus caballos a la sombra de un olivo: «Lur chevals laisent dedesuz un'olive» (v. 2705); al encontrar a Roldán muerto, Carlomagno se desmaya y lo acuestan bajo un pino: «Prenent al rei, si-l drecent suz un pin» (v. 2884). No hemos extremado la búsqueda en otras chansons de geste, pero no dejarían, según creemos, de cedernos interesantes ejemplos adicionales, como, por ejemplo, en la Aliscans, donde el conde Guillermo de Orange se sube al caballo a la sombra de una oliva: "Vint un perron soz l'olive ramee» (Claude Régnier [ed.], Aliscans: Rédaction A, 2 tomos, Paris, Honoré Champion, 1990, I, v. 2429); en La prise d'Orange (redacción $A B$ ), los mensajeros saracenos van en busca del rey Tiebaut de África: «Tant que il vinrent en la cité d'Aufrique. / Il descendirent en l'ombre soz l'olive» (Claude Régnier [ed.], Les rédactions en vers de "La prise d'Orange», Paris, C. Klincksieck, 1966, pág. 148, vv. 1271-1272); en Le pèlerinage de Charlemagne, el emperador, en conversación con la reina, la lleva bajo un olivo: «Il la prist par le poin desuz un oliuer» (Eduard Koschwitz [ed.], Karls des Grossen Reise nach Jerusalem und Constantinopel: Ein altfranzösisches Heldengedicht, 6ta ed., Leipzig, O.R. Reisland, 1923, v. 7); o bien en el poema épico provenzal de Girart de Rossilho, donde el protagonista: «Per tant est descenduz desoz un pin» (W. Mary Hackett [ed.], Girart de Roussillon: Chanson de geste, 3 tomos, Paris, A. \& J. Picard, 1953-1955, v. 2669) y, tras oír misa, sale de un monasterio y se sienta debajo de un pino: «E pois s'en eissi fors desos un pin» (v. 3840). Nótese el parecido genético que señala Milá y Fontanals entre nuestro hemistiquio y un verso de la versión provenzal del Fierabrás: «Lo sarrazi dissent / sotz un arbre folhat» (De la poesía, pág. 357; ed. de 1959, pág. 447). Y volviendo a España, acordémonos del conocidísimo romancillo infantil de Las tres cautivas: "A la verde, verde, / a la verde oliva...».

${ }^{14}$ Los pliegos poéticos en la colección del Marqués de Morbecq (Siglo XVI), ed. Antonio Rodríguez-Moñino, Madrid, Estudios Bibliográficos, 1962, pág. 167a. 
Dina, la hermosa protagonista también va a la sombra de tejados: «Se esparte la linda Dinah; / se va para ande su se[nyyor], // a solombra de tejado, / ke non la empanyyara el sol». ${ }^{15}$

$\mathrm{Y}$ también es formulístico nuestro tercer hemistiquio: mirando estaba o bien miraba. Compárense:

Helo helo por do viene mirando estaua a valencia

el moro por la calçada . . . como estaba tan bien cercada.

(Amberes, sin año: fol. 179 vo. = Primav. 55)

hallola lauando el rostro mirando se esta avn espejo

El postrero que lo mira Yncó rodilla en el suelo

Miraua de campo viejo miraua la mar de españa mira naos y galeras

(Amberes, van y otras venian.

que ya se auia leuantado el cauello destrançado

(Pliegos de Praga, I, 331)

es el dotor De la Parra. mirándole esta la cara.

(Maestro León, núm. 59)

el rey de Aragon vn dia como menguaua y crecia

Sobre Baça estava el rey, Mirava las ricas tiendas mirava las huertas grandes mirava el adarve fuerte mirava las torres espesas, lunes después de yantar. y mirava el arraval; que tenía la çiudad; que no las puede contar.

${\text { (Cancionero musical, no. } 135)^{16}}^{16}$ qu'estavan en su real;

Es típico del lenguaje romancístico, además, el hipérbaton que coloca el verbo auxiliar tras el gerundio, como, por ejemplo, en las maldiciones iterativas de don Beltrán (y también de Gaiferos): «Maldiciendo iba el vino, / maldiciendo iba el pan», etc. (Primav. 185a; 173). La tradicionalidad del sintagma la comprueban los abundantísimos casos presentes aún en el romancero judeo-español moderno, según constan en el Catálogo-indice de la colección del Archivo Menéndez Pidal: «Volando estaba la garza» (B19.1);

${ }^{15}$ Samuel G. Armistead y Joseph H. Silverman, The Judeo-Spanish Ballad Chapbooks of Yacob Abraham Yoná, Berkeley-Los Ángeles-London, University of California Press, 1971, núm. 8.12-13.

${ }_{16}$ El ms. del Maestro León se cita por la ed. de Zorita, DiFranco y Labrador, Poesías del Maestro León. El Cancionero musical de Palacio (Siglos XV-XVI), lo citamos en la ed. de José Romeu Figueras, 2 tomos, Barcelona, C.S.I.C., 1965. El mismo romance figura bajo el núm. 330 en la ed. de Francisco Asenjo Barbieri, Cancionero musical de los siglos XV y XVI, Madrid, Tipografia de los Huérfanos, 1890; 2. ${ }^{a}$ ed., Málaga, Gráficas Urania, 1987. 
«Durmiendo estaba Parisi» (o bien «(se) está») (F4.2-7); «Labrando estaba (o «está») la reina» (J4.9, 34; M9.4); «Paseando está Silvana» (P1.4); «Maldiziendo va el buen rey» (X4.20-21). ${ }^{17}$ Lope, con su infalible -e inimitable - conocimiento de la poesía tradicional, remeda el recurso en su comedia, Las pobrezas de Reinaldos, en un romance de su propia composición:

Labrando estaba Claricia, para Reinaldos, su esposo,

una sobreveste blanca que andaba en el monte a caza... ${ }^{18}$

El cuarto y último hemistiquio, desconocido en las demás versiones de Calaínos (Amberes, sin año y Valderrábano), encuentra igualmente su eco formulístico en otros varios romances:

Por el val de las estacas, En su cauallo Bauieca

Santa fe quan bien pareces

... essas que vienen de guerra passo el Cid a medio dia.

o quan bien que parecia.

(Pliegos de Cracovia, pág. 60 = Primav. 31)

en los campos de granada.

(Silva de 1550 , pág. $316=$ Primav. 89 )

o quan bien le parescian.

(Silva de 1550 , pág. $321=$ Primav. 101 $)^{19}$

${ }^{17}$ Samuel G. Armistead, con la colaboración de Selma Margaretten, Paloma Montero, y Ana Valenciano, y con transcripciones musicales de Israel J. Katz, El romancero judeo-español en el Archivo Menéndez Pidal (Catálogo-índice de romances y canciones), 3 tomos, Madrid, C.S.M.P., 1977.

${ }_{18}$ Menéndez Pelayo, Tratado de los romances viejos, II, pág. 325.

19 Citamos por las ed. de María Cruz García de Enterría, Pliegos poéticos españoles de la Biblioteca Universitaria de Cracovia, 2 tomos, Madrid, Joyas Bibliográficas, 1975; y Antonio Rodríguez-Moñino, Silva de romances (Zaragoza, 1550-1551). Véase también la edición de las versiones antiguas del Val de las Estacas, con aparato crítico exhaustivo, en Jesús Antonio Cid, «Semiótica y diacronía del 'discurso' en el Romancero tradicional: Belardo y Valdovinos, El Cid pide parias al moro", RDTP, 37, 1982, págs. 80-83. Falta la fórmula que aquí nos ocupa en las dos preciosas versiones que Maximiano Trapero ha descubierto en la Isla de La Gomera (Maximiano Trapero, Romancero de la Isla de La Gomera, con la colaboración de Elena Hernández Casañas y Lothar Siemens Hernández, Madrid, Cabildo Insular de la Gomera, 1987, núms. 25-25bis). El último texto aquí citado representa Las quejas de Alfonso $V$. El romance sigue cantándose en la tradición de los gitanos bajoandaluces, pero no ha sobrevivido el verso que aquí nos interesa (Luis Suárez Ávila, «El romancero de los gitanos bajoandaluces: Del romancero a las tonás», Dos Siglos de Flamenco: Actas de la Conferencia Internacional, Jerez 21-25 junio 88 [Jerez, Fundación Andaluza de Flamenco, 1989], págs. 29-129: v. 104). Nuestra fórmula también se da en un romance culto sobre La duquesa de Loreyna, aplicado al traidor Lembrot: «el termino no es cumplido / quando ya Lembrot venia // con los dos tios consigo / o quan bien que parecia» (Cancionero de Amberes, 1550, pág. 196). Para la exclamación ¡Cuán bien!, nótense estos versos-cargados de intenciones-de Las bodas en París: «Quan bien que guia la dança / esta doña Beatriz // Quan bien que se la miraua / el buen conde don Martin» (Cancionero de Amberes, 1550, pág. 322 = Primav. 157). 
En 1934, doña Carolina Michaëlis de Vasconcelos publicó la segunda edición de su libro pionero sobre los Romances Velhos em Portugal (Coimbra, Universidade), que sigue siendo, como siempre ha sido, de consulta obligatoria para nuestro conocimiento de las etapas tempranas del Romancero. En lo que se refiere a la exhaustiva compulsa de fuentes literarias portuguesas realizada con tanto esmero por doña Carolina, todavía no existe nada comparable para la literatura clásica española. ${ }^{20}$ Huelga decir cuánto aprenderíamos una vez realizada tan gigantesca tarea. Valgan los versos recogidos por el Bachiller Luis Peraza como una exigua y aislada, pero interesantísima muestra de lo que nos espera.

${ }^{20}$ Véase el crucial estudio de Giuseppe di Stefano, «Il 'romancero viejo' in Portogallo nei secoli XV-XVII (Rileggendo C. Michaëlis de Vasconcelos)», QP, 11-12, 1982, págs. 27-37. Como un comienzo, ya de gran utilidad, nótese el catálogo de citas romancísticas en ensaladas áureas de Giuliana Piacentini, «Romances en ensaladas y géneros afines», AFE, 1, 1984, págs. 1135-1173. 